\title{
Yellow swelling around the eyes: periocular lymphoma
}

\section{H.J. Bovenschen MD PhD, E.J.F.M de Kruijf MD}

Previously published at www.cmaj.ca

A 49-year-old woman presented with gradual onset of swelling and yellowish discoloration around both eyes (Figure 1). Nine years earlier, she had been assessed for persistent lymphocytosis, which was thought to represent stage 0 chronic lymphocytic leukemia, for which no treatment was needed. During follow-up, her peripheral blood cell counts remained stable and no palpable lymphadenopathy had developed. At this presentation, the patient was found to have swollen intranasal mucosa and periocular yellowish subcutaneous nodules, and no erythema or scaling. She had no palpable lymphadenopathy or other abnormalities.

Biopsy of the subcutis of the right upper eyelid showed normal epidermis but there was a massive dermal and subcutaneous infiltrate of B-cells (CD20+, CD79a+, Bcl-2+, אchain+) and hemosiderin-loaded macrophages. CD23 and CD10 were negative. Cyclin-D1 was negative, and proliferation marker Ki-67 (MIB-1) was sparingly positive. T-cell markers (CD2, CD3, CD5 and CD7) were negative. This histopathologic and immunophenotypical examination gave results consistent with an extranodal marginal zone B-cell lymphoma of mucosa-associated lymphoid tissue.

The colour of the skin lesions was explained by the accumulation of hemosiderin-laden macrophages. There was no evidence of bleeding on examination or in the patient's history. Results of a bone marrow biopsy were consistent with marginal zone B-cell lymphoma, showing extensive infiltration of B cells that were immunophenotypically identical to the cutaneous B-cell infiltrate. Treatment with a combination of chemotherapy and immunotherapy (cyclophosphamide, vincristine, prednisone and rituximab) resulted in complete remission and resolution of the skin lesions (Figure 1).

Extranodal marginal zone B-cell lymphomas account for up to $80 \%$ of periocular lymphomas. The tumours originate in mucosa-associated lymphoid tissue in the ocular adnexa.

From the Department of Dermatology (Bovenschen), Radboud University Nijmegen Medical Center, Nijmegen and the Department of Internal Medicine (de Kruijf), Gelderse Vallei Hospital, Ede, the Netherlands.

\section{CMAJ 2010. DOI:10.1503/cmaj.090955}

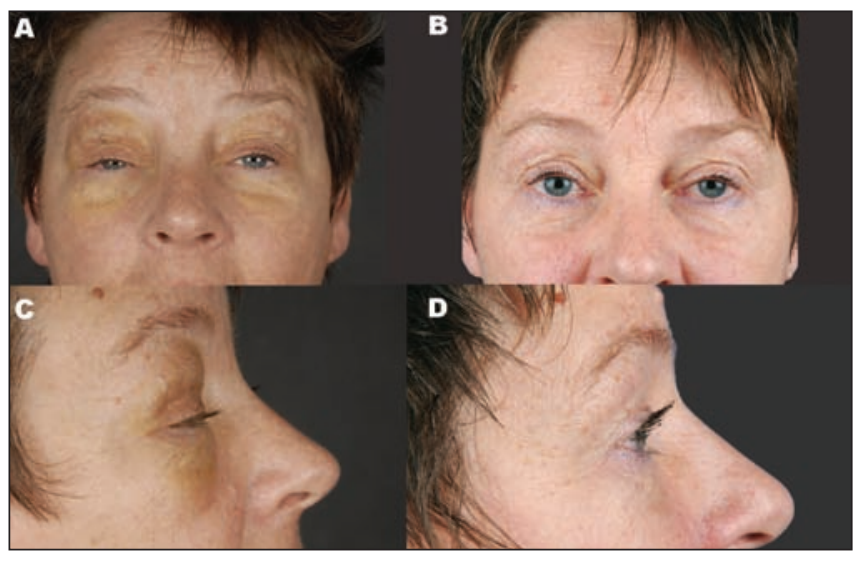

Figure 1: (A) Front view of a 49-year-old patient before treatment, showing periorbital yellowish discoloration with indurated subcutaneous nodules. (B) Front view after combination of chemotherapy and immunotherapy (background colour adjusted for ease of comparison). (C) Side view before treatment. (D) Side view after treatment.

Most ocular adnexal lymphomas are primary tumours but up to one-third are secondary tumours that develop in patients with disseminated lymphoma. ${ }^{1}$ Localized periocular lymphoma can be treated with radiotherapy alone ${ }^{2}$ but systemic involvement requires chemotherapy, alone or in combination with immunotherapy. With this approach, the disease can be controlled for years; however, the persistent nature of this lymphoma can often lead to relapse. ${ }^{3}$

This article has been peer reviewed.

Competing interests: None declared.

\section{REFERENCES}

1. Stefanovic A, Lossos I. Extranodal marginal zone lymphoma of the ocular adnexa. Blood 2009; 114:501-10.

2. Decaudin D, Dendale R, Lumbroso-Le Rouic L. Treatment of mucosa-associated lymphoid tissue-type ocular adnexal lymphoma. Anticancer Drugs 2008;19:673-80.

3. Suh C, Huh J, Roh JL. Extranodal marginal zone B-cell lymphoma of mucosaassociated lymphoid tissue arising in the extracranial head and neck region: a high rate of dissemination and disease recurrence. Oral Oncol 2008;44:949-55. 